\title{
MÁS ALLÁ DEL TELAR: EL MUNDO DEL TRABAJO FEMENINO EN LA ASTURIAS DEL SIGLO XVIII
}

\author{
Beyond the loom: The professional world of the Asturian women of the $18^{\text {th }}$ century
}

\author{
Patricia SuÁrez Álvarez \\ Alberto MORÁn CORTE \\ Universidad de Oviedo
}

Fecha de recepción: 6-III-2011

Fecha de aceptación: 8-IV-2011

Resumen: En el Siglo de la Razón proliferaron los tratados dónde, por primera vez en la historia, se ponía de relieve la necesidad de educar de forma conveniente a las mujeres. Sin embargo, a pesar del reconocimiento que los Ilustrados otorgaron al sexo femenino, siguieron relegando a éstas a las paredes del hogar, exhortándoles a quedarse fuera del mundo del trabajo extra-doméstico, reservado sólo para los hombres de la familia. No obstante, la necesidad obligaba, y cuando los recursos u hombres de una casa escaseaban, la mujer tenía que salir a buscarse el sustento. Este es el caso de cientos de mujeres del Principado de Asturias, dónde, a mediados del siglo XVIII, la realidad femenina difería de lo que lo que se consideraba ideal. Este trabajo arrojará pues luz, en un campo hasta ahora desconocido: el del mundo profesional de las mujeres asturianas del Setecientos, dónde comprobaremos cómo en ocasiones llegaban a adquirir, gracias a su status profesional, papeles relevantes dentro de la sociedad.

Palabras Clave: Ilustración, trabajo doméstico, Asturias, Mujeres, trabajo.

ABSTRACT: In the Age of Reason, the treatises about the women's good education began to be popular. However, even if of the Illustrated authors conferred importance on the females, they continued considering home life as the ideal for women, and exhorted them to stay out of the extra-domestic work world. Nevertheless, poverty forced to women to work outside when the economic resources were insufficient. This is the case of hundreds of women in Asturias, where, in the middle of the $18^{\text {th }}$ century, the reality was completely different from the ideal. This paper will allow us to discover a unknown subject: the professional world of the Asturian women of Enlightenment.

Keywords: Enlightenment, Household, Asturias, Women, Work. 
Las transformaciones políticas, sociales y económicas que durante el Siglo de la Razón fueron produciéndose paulatinamente en Europa, pusieron sobre la palestra una serie de campos de debate que hasta entonces, apenas habían sido examinados. Entre otras se abordaron cuestiones como la igualdad de los hombres o la necesidad de reformas económicas, que, de forma tangencial, plantearon otras discusiones acerca del rol de la mujer en la sociedad, su equiparación con el hombre y el derecho de las féminas a la educación. Se reabrió así lo que algunos autores llaman la querella de los $\operatorname{sexos}^{1}$, de la que participarían literatos y políticos de distintos ámbitos y de cuyas discusiones surgieron nuevas visiones sobre la mujer, llegando a consolidarse dos modelos: la aristócrata participante de lo público y la mujer doméstica ${ }^{2}$.

El ideal de mujer doméstica, buena madre y buena esposa, salió triunfante entre los moralizantes de la época, olvidándose no obstante, de aquella tercera mujer que, no pudiendo acceder a los salones sociales, tampoco podía emplearse de forma exclusiva en el hogar: la mujer trabajadora.

La mayor parte de las mujeres asturianas se alejarán de los estereotipos, ofreciéndonos una realidad muy diferente a la que nos muestran literatos y tratadistas.

\section{LA VISIÓN LITERARIA DE LAS MUJERES: MORATÍN Y GÁLVEZ}

"Esto y mucho más peligra reino en que manda mujer". Así hablaba Jehu en referencia a la influencia que Jezabel, reina consorte, tenía sobre su esposo Acab, rey de Israel. Lasciva, tirana, cruel, de este modo nos presenta Tirso de Molina a la reina que, ante un marido de carácter indeciso, toma las riendas del gobierno en la obra La mujer que manda en casa. La visión negativa de esta soberana contrasta con la que el dramaturgo ofrece de la madre del futuro Fernando IV, María de Molina, protagonista de La prudencia de la mujer, cuyo arrojo y buen hacer no tendrá otro fin que no sea el de conservar la corona para su hijo, haciendo gala de una virtud muy recurrente en la literatura española de la época: la prudencia. Prudencia frente a vehemencia, el silencio frente a la palabra. A través de este sencillo ejemplo, vemos cuál era el lugar que la sociedad de la Época Moderna reservaba a las féminas: las bambalinas.

1 FRANCO RUBIO, Gloria, "La contribución literaria de Moratín y otros hombres de letras al modelo de mujer doméstica" en Cuadernos de Historia Moderna. Anejos, 6, Madrid, 2007, pág. 224.

2 Ibidem, pág. 230.

3 MOLINA, Tirso de, "La mujer que manda en casa" en Obras de Tirso de Molina IV, BAE, Tomo CCXXXVIII, Madrid, Ediciones Atlas, 1970, pág. 186. 
Algunos literatos del Siglo de las Luces siguieron alabando la circunspección en la mujer, otorgándole no obstante cierta visibilidad al poner de relieve algunos de sus problemas y legitimar su derecho a la educación. Tal fue el caso de Leandro Fernández de Moratín, quien en obras como El Sí de las Niñas o El Viejo y las Niñas, defiende la libertad de elección de matrimonio de las jóvenes que, a su vez, deben asomarse al conocimiento y la educación. Sin embargo las cualidades peyorativas de la mujer, de las que tanto eco se habían hecho sus homólogos del siglo pasado, no se escapan a algunos personajes del autor. En La Moj̈gata, doña Clara finge abrazar la vocación religiosa para huir de lo que probablemente sería su destino sin remisión: un matrimonio a instancias de los deseos de su padre. El carácter de la protagonista, sumiso y humilde, tal como se espera de una joven de su rango y educación, y su piedad, resultan, no obstante, ser totalmente engañosos, y Clara contrae a su vez un matrimonio clandestino. Lo que podría ser, a ojos actuales, un acto de rebelión, Moratín lo convierte en una maniobra hipócrita y astuta, dando una visión en extremo negativa de la hija frente a la actuación del padre, justificada, en último extremo, en el paternalismo.

Un punto de vista femenino dará, por los mismos años, María Rosa Gálvez. La dramaturga no se detiene únicamente en la libertad de elección de la mujer, ahondando en temas más profundos y proporcionando soluciones más prácticas que las de su contemporáneo Moratín ${ }^{4}$. Así, la esposa de El Egoísta no será mal vista por pretender separarse de su marido desafecto y en La familia a la moda, la imagen de los hombres de la casa, jugadores, irresponsables y torpes, aparece contrapuesta al carácter resolutivo e inteligente de Guiomar Pimpleas, que termina por solventar las desavenencias de la familia. No obstante, y a pesar del tono alegre de algunas de sus obras, sus tragedias dan cuenta de un callejón sin salida para las mujeres, que encuentran en la muerte voluntaria -Safo, Florinda o Blanca de Rossi- una vía de escape a una sociedad que, haciendo caso omiso de algunas posiciones oficiales, siguió relegándolas al papel de espectadoras.

\section{LA VISIÓN DE LA MUJER EN LOS TRATADISTAS ASTURIANOS DE LA ILUSTRACIÓN: DE LOS CONSEJOS MORALES DE PUMARADA AL PRAGMATISMO DE CAMPOMANES}

Si bien la literatura nos mostraba una versión utópica de la mujer o de cómo ésta debía comportarse, la realidad hacía que políticos y tratadistas ilustrados abordasen también cuestiones relativas al trabajo y educación femeninas, en pos del progreso del país.

4 WHITAKER, Daniel S., "La mujer ilustrada como dramaturga: el teatro de María Rosa Gálvez" en VILANOVA, Antonio (coord.), Actas del X Congreso de la Asociación Internacional de Hispanistas, PPU, Barcelona, 1989. 
Se suele hablar del Setecientos como una centuria de luces y sombras en cuanto a los cambios en la vida e imagen que a la mujer se refiere ${ }^{5}$. Aunque proliferan los escritos en los que se aboga por la relevancia de la mujer en la sociedad, su derecho a la educación y la igualdad de ésta con el hombre, sólo en contadas excepciones no se hace desde un punto de vista paternalista y limitado. Los tratadistas del Siglo de las Luces reconocieron las capacidades de la mujer concediéndoles algunas prerrogativas sociales, pero entre líneas no les otorgaron más libertad que aquella que les correspondía a las de su género. Sólo en boca de mujeres como Inés Joyes o Josefa Amar, ya a finales del siglo XVIII, se planteó una auténtica igualdad de sexos, en cuyos tratados, rasgos como el de la inteligencia sobresaldrán por encima de las cualidades de "madre tierna" y "esposa fiel".

En el contexto español, y hasta mediados de siglo, buena parte de las enseñanzas didácticas y moralistas procedían del ámbito religioso. En lo que a la visión de las féminas se refiere, eclesiásticos como Fray Diego José de Cádiz o el Padre Calatayud continuaron con la mirada despectiva de la etapa anterior ${ }^{7}$ y en Asturias, Fray Toribio de Pumarada no será una excepción.

Aunque sólo se le conoce la autoría del tratado dedicado a su sobrino con instrucciones espirituales y temporales, la obra del dominico asturiano Fray Toribio de Santo Tomás y Pumarada merece especial detenimiento a tenor de la escasa atención que este escrito ha recibido ${ }^{8}$. El Arte General de Grangerias, escrito entre 1711-1714, engloba dos libros, De la Grangería Espiritual y De la Grangería Temporal, que el eclesiástico escribió desde el Convento de San Pablo de Valladolid. Dirigida a su sobrino, heredero de las posesiones del autor, el escrito es una compilación de normas de comportamiento -espirituales- y de lecciones acerca del modo de llevar una hacienda -temporales-. Entre las lecciones espirituales, aborda

5 BOLUFER, Mónica, “Transformaciones culturales. Luces y sombras” en ORTEGA, Margarita, LAVRIN, Asunción y PÉREZ CANTÓ, Pilar (Coords.) Historia de las mujeres en España y América Latina. Volumen II. El mundo moderno, Madrid, Cátedra, 2005, pp. 479-510. 6 Ibidem. pp. 479-510

7 PEÑAFIEL RAMÓN, Antonio, Mujer, mentalidad e identidad en la España moderna (siglo XVIII), Murcia, Editum, 2008, pp. 43-48.

8 SANTO TOMÁS Y PUMARADA, Fray Toribio de, Arte General de Grangerías, Gijón, Muséu del Pueblu d'Asturies, 2006. Obra transcrita por Jesús Suárez López y María José Priesca Balbín, y que cuenta con un interesante estudio preliminar de Juaco López Álvarez. Pese al interés que tiene esta obra, apenas existen referencias a la misma: SUÁREZ GARCÍA, Raquel y LÓPEZ ÁLVAREZ, Juaco, "Léxico asturiano en un tratado de granjería del años 1711 (I)" en Revista de Filoloxía Asturiana, 1, Uviéu, 2001, pp. 170-70; SUÁREZ GARCÍA, Raquel y LÓPEZ ÁLVAREZ, Juaco, "Léxico asturiano en un tratado de granjería del años 1711 (I)" en Revista de Filoloxía Asturiana, 2, Uviéu, 2002, pp. 9-52; ÁLVAREZ CASTRILLÓN, José Antonio, "Arte general de Grangerías (1711-1714) de Fr. Toribio de Santo Tomás y Pumarada” en BIDEA, 170, 2007, pp. 161-164. 
el complejo mundo de las relaciones de jerarquía y familiares del campo asturiano del siglo XVIII ${ }^{9}$. Como corresponde a un buen moralista, a Fray Toribio no se le escapan las recomendaciones sobre las mujeres a su sobrino, alentándole a que no les confíe ningún secreto y que huya de su concupiscencia. Podemos ver de nuevo esa visión negativa respecto a la mujer, cuyos defectos, indiscreción, lascivia, hipocresía, nos han sido mostrados, como ya se comentó con anterioridad, como tópicos literarios. Así, cuando advierte de lo pecaminoso de la fornicación o del estupro, la culpabilidad masculina aparece mermada frente al "vicio" femenino. Sin embargo, tanto delito tiene la mujer que consiente como la que no lo hace dentro del matrimonio. El monje escusa a algunos adúlteros porque "entraron en el oficio despechados y enfadados de sus propias, porque les niegan el cuerpo cuando se le debian de dar" y anota que "mayor pecado es negar, que adulterar"10. Bien es verdad que previamente, enumera varios casos, con todo detalle, en los que la mujer tiene el derecho de negarse a tener trato carnal con su esposo, como son las "desviaciones sexuales" que la moral dieciochesca no contempla.

Con todo, insta al esposo a tener un trato cariñoso con su cónyuge aunque el afecto no debe mostrarse en exceso "porque son livianas de cascos, y luego, si se reconocen del marido muy queridas, se le quieren engreir, y sobre ñiflosas son poco sufridas" $" 11$. Entre otras recomendaciones, Fray Toribio indica que no debe dejar las llaves de las arcas del dinero a la esposa, ni hacer caso de sus lágrimas o suspiros, ni de sus necias preguntas ${ }^{12}$. La casada ha de ser discreta, callada y solícita, cualidades que, en caso de carecer de ellas, es deber del hombre "meter a su muger en tales caminos" usando "mucha pachorra, repetición, gran cariño y blandura de razones. Porque este ganado mejor se enseña y doma por amores que por dolores"13.

Con estas descripciones, sobra señalar la consideración que de la mujer tenía el religioso a la que también designa quehaceres específicos dentro del hogar campesino. Las mujeres deben saber hilar, coser, amasar pan, guisar, tener su manada de gallinas, criar cerdos y mantener "cada preseo en su sitio, que no sirva de tropiezo y se balle prestamente cuando se busca"14.

A pesar de lo expuesto, podemos atisbar un espíritu ilustrado en el monje, no sólo por el fin didáctico de su obra sino por la defensa que hace de la educación de las jóvenes. Fray Toribio no menosprecia la inteligencia de la mujer a la que se le debe enseñar a leer y escribir porque "se van haciendo agudas, entendidas, discretas y de babilidad para governar un lugar, quanto más una cassa"15.

9 SANTO TOMÁS Y PUMARADA, Fray Toribio de, Arte General de Grangerías, Gijón, Muséu del Pueblu d'Asturies, 2006, pág. 24-25.

10 Ibídem, pág. 244-245.

11 Ibidem, pág. 250.

12 Ibídem, pág. 249-250.

13 Ibídem, pág. 248.

14 Ibídem, pág. 230.

15 Ibídem, pág. 220. 
Si esto escribía Fray Toribio Pumarada, pocos años después el benedictino y asturiano de adopción Fray Benito Jerónimo Feijoo, salía en defensa del género femenino en su Discurso XVI. El Teatro Critico Universal, comenzado a escribir en 1725, época en que ya gozaba del título de Abad de San Vicente de Oviedo, aborda, de forma muy aséptica, distintos problemas sociales y económicos, que no dejarán de estar de actualidad durante el Siglo de las Luces, de forma que, al propio fraile se le distingue como el primer ilustrado asturiano. Su discurso Defensa de las mujeres está inserto en el contexto de polémica sobre las diferencias entre hombres y mujeres que, en el siglo XVIII, discurría en toda Europa, y cuyo origen hunde sus raíces en la Edad Media ${ }^{16}$. Como reacción a la corriente, por lo demás común, que definía a la mujer en términos despectivos, el Padre Feijoo lanza esta diatriba en la que él mismo señala que "defender a todas las mijeres, viene a ser lo mismo que ofender a todos los hombres"17. Por primera vez, se impulsa la idea de la igualdad racional de ambos sexos de forma pública y notoria cuestionando la incapacidad de las mujeres para gobernar. El tema del fomento de la educación femenina, en todo punto equiparable a la de los hombres según el autor, sería una pieza fundamental de su discurso lógico cuyas aseveraciones se consideran vigentes hoy día. Como contrapunto decir que, las cualidades exaltadas en la mujer -vergüenza, candidez, docilidad- que a menudo identifica con otras masculinas -constancia, prudencia,...- recuerdan, al fin y al cabo, a las enaltecidas en épocas pasadas ${ }^{18}$.

En la segunda mitad del siglo, se generalizó la idea de igualdad intelectual que el Padre Feijoo expresaba. Muchos fueron los ilustrados que pregonaron la idea de la incorporación de la mujer al trabajo y la formación, y en la elite social comenzaron a proliferar las asociaciones y reuniones femeninas, las que, al igual que las de sus homólogos masculinos, tenían un marcado carácter erudito.

La postura de Gaspar Melchor de Jovellanos, uno de los más insignes ilustrados asturianos, correría entre dos aguas. El Jovellanos público defendía la idoneidad de la mujer para el trabajo y sus cualidades como educadoras de los hijos y compañeras inseparables del hombre, por lo que no es de extrañar que abogase por la presencia de mujeres en la Sociedad Matritense en $1786^{19}$, aunque señalaba que esta debía ser moderada, no

16 MORANT, Isabel. "Hombres y mujeres en el discurso de los moralistas. Funciones y relaciones" en Historia de las mujeres en España y América Latina. Volumen II. El mundo moderno, Cátedra, Madrid, 2005, pág. 28.

17 JERONIMO FEIJOO, Fray Benito, "Discurso XVI. Defensa de las mujeres" en Teatro Crítico Universal, BAE, Tomo LVI, Madrid, Ediciones Atlas, 1953, pág. 50.

18 Ibidem, pp. 50 a 58.

19 JUNCEDA AVELLO, Enrique, "La mujer en Jovellanos" en BIDE $A, 133$, Oviedo, 1990, pp. 3-18. 
excediendo de la "media docena" las propuestas de nombramiento ${ }^{20}$. En privado, sus cartas y diarios mostraban el verdadero rasero con que el gijonés las medía, juzgando a las mujeres como caprichosas y necias, de recias costumbres inamovibles que afirmaba eran "los fieros males de mi patria"21.

De su hermana Josefa, recordada sobre todo por su figura de literata, destaca su papel de beneficiaria de instituciones que procuraban un futuro a las mujeres más necesitadas, como el Hospicio de Oviedo y la cárcel de mujeres de Oviedo aunque su obra pía más conocida fue la fundación de una escuela de niñas en Gijón en el año de 1794. En sus disposiciones testamentarias, llevadas a cabo antes de entrar en el convento de las Agustinas Recoletas en Gijón, recogía las normas por las que esta escuela debía de regirse ${ }^{22}$. Entre otras cosas, enumeraba las enseñanzas que las alumnas debían de recibir, el perfil de la maestra que debía tutelar la escuela -joven, soltera o viuda y paciente-, el calendario escolar y otras muchas instrucciones como las relativas a los castigos corporales de los que Josefa Jovellanos se mostraba totalmente en contra ${ }^{23}$. La poetisa desviaba así la mirada hacia la mujer que en buena medida era la mayoritaria entre las asturianas, la mujer de las "clases" desfavorecidas.

A solventar estos y otros problemas de las "clases" desfavorecidas estaban destinados los tratados del Conde de Campomanes, Discurso sobre el fomento de la Industria Popular y Discurso sobre la Educación de los Artesanos y su fomento, de 1774 y 1775 respectivamente. Con la intención de desterrar el ocio entre la población del país y otras costumbres perjudiciales para el progreso económico de este, expone estos dos tratados donde condena, entre otras cosas, costumbres como la rigidez de los gremios, que a su juicio, impedían el avance social y económico. En el Discurso XVII, De las ocupaciones mujeriles a beneficio de las artes, aboga por la incorporación de la mujer al trabajo fuera del ámbito doméstico, a las que, previamente, se las debe dar una buena educación.

Centrándose sobremanera en los oficios textiles y relacionados con los comestibles señala una serie de trabajos que no sólo pueden desempeñar las mujeres si no que resultan de mayor idoneidad para ellos que los hombres. La elaboración de tejido, bordados, adornos, botonaduras y encajes, así como el sazonado de alimentos serían algunos de ellos ${ }^{24}$.

20 MENÉNDEZ GONZÁLEZ, Alfonso, El barranco de las asturianas. Mujer y sociedad en el Antiguo Régimen, Oviedo, KRK, 2006, pp. 247-248.

21 JUNCEDA AVELLO, Enrique, "La mujer...”, pág. 15.

22 RUIZ DE LA PEÑA, Álvaro, "Filantropía y educación en el siglo XVIII: las disposiciones testamentarias de Josefa Jovellanos" en VV. AA., Estudios dieciochistas en homenaje al Profesor José Miguel Caso González. Volumen II, IFESXVIII, Oviedo, 1995, pp. 285-294.

23 ÁLVAREZ FAEDO, María José, “Josefa Jovellanos y la educación de la mujer en el siglo XVIII” en Boletín Jovellanista, 5, Gijón, 2004, pp. 15-34.

24 CAMPOMANES, Conde de, Discurso sobre el fomento de la industria popular. Discurso sobre la educación popular de los artesanos y su fomento, ANES, Gonzalo (prol.), GEA, Oviedo, 1991, pág. 271. 
A todo esto, habría que añadir el hilado y cardado de la lana, oficios todos ellos adecuados a "las fuerzas mujeriles"25. De este modo, "podrán contribuir en parte al bien general de la nación, de que su actual situación las tiene privadas, aunque sin culpa suya, por depender de otros su crianza civil’"26.

Vemos pues que el discurso de Don Pedro Rodríguez de Campomanes gira sobre el tópico ilustrado por excelencia del servicio al bien común, del que las mujeres, tan aptas como los hombres si se les proporciona una buena educación, no estaban eximidas.

Cabe señalar que de la ociosidad y desidia de las que acusa a las mujeres de la mayoría de las provincias del país, se escapaban las gallegas, asturianas, montañesas, vizcaínas y guipuzcoanas, de las que observa que "van en los barcos a pescar en el mar; llevan a vender el pescado fresco desde los puertos de mar tierra adentro, o a los mercados, cultivan las tierras por si mismas: son tenderas, panaderas, que amasan y venden el pan'"27.

\section{LA REALIDAD FEMENINA: LAS MUJERES TRABAJADORAS ASTURIANAS}

El discurso de Campomanes, más cercano a la realidad, nos pone sobre la pista de la actualidad del Setecientos asturiano, dónde muchas de sus mujeres compaginaban las labores domésticas con trabajos fuera del hogar.

La apuesta por el trabajo femenino extradoméstico, se suele poner en relación con las transformaciones económicas del siglo XVIII. La nueva economía de mercado y la incipiente industrialización ponen de relieve la necesidad de nuevos brazos para trabajar, de tal forma que en determinados oficios se empiezan a contemplar tareas para niños y mujeres ${ }^{28}$.

En el Principado de Asturias las descripciones de viajeros y otros contemporáneos nos hablan de al menos dos tipos de mujeres: la histérica y delirante de la que nos ha dejado testimonio el doctor Casal, achacando estos males a las doncellas ociosas ${ }^{29}$, y la muyeruca asturiana, fuerte y con

25 Ibídem, pág. 266.

26 Ibídem, pág. 272.

27 Ibidem, pág. 262.

28 Monserrat Carbonell hace referencia a la exposición del Conde del Carpio que en 1779 declara que hay determinados oficios en su fábrica que por la delicadeza de su trabajo, son muy adecuados para mujeres y niños. En palabras del noble, estos serían los de cordones, bordados, encajes y otras manufacturas. CARBONELL, Monserrat. "Trabajo femenino y economías familiares" en Historia de las mujeres en Españay América Latina. Volumen II. El mundo moderno, Cátedra, Madrid, 2005, pp. 251-254. 29 CASAL, Gaspar, Historia Natural y Médica del Principado de Asturias, TOLIVAR FAES, José Ramón (ed.), Servicio de Publicaciones del Principado de Asturias, Oviedo, 1988, pp. 133 140. MENÉNDEZ GONZÁLEZ, Alfonso, El Barranco... pp. 239-246. 
carácter, de las que el Conde de Laborde señalaba que en ausencia de sus maridos "se encargan de cultivar la tierra y lo hacen con constancia y vigor' 30 .

Probablemente, eran estas mujeres las que aparecían como trabajadoras en las Respuestas Particulares del Catastro de Ensenada, cuando éste se realizó en Asturias entre los años 1752-1753 ${ }^{31}$.

Partiendo de la actual división del territorio asturiano en tres circunscripciones electorales -Occidente, Centro y Oriente-, hemos tomado como base para nuestro estudio el centro de la región, que en 1753 sumaba el 48,9\% del total de la población del Principado ${ }^{32}$.

La mayoría de los ejemplos en los que hemos basado nuestro trabajo se corresponden con el ámbito rural. La excepción a esta norma es la parroquia de Villaviciosa, inclusa en el concejo del mismo nombre, y las villas marineras de Gijón y Candás. Sin embargo únicamente en el primer caso hemos podido trabajar con los datos "urbanos" de manera aislada, debido a que en las Respuestas Particulares del concejo se especifica a qué feligresía pertenece cada jefatura familiar. En el caso de Gijón y Candás, como veremos más adelante, se pueden intuir como algunas de las profesiones anotadas se corresponderían sin duda con el ámbito urbano.

30 MASES, José Antonio, Asturias vista por viajeros románticos extranjeros y otros visitantes y cronistas famosos. Siglos XV al XX. Volumen I, Trea, Gijón, 2001, pág. 211.

31 Esta documentación, forma parte de otra más amplia con el nombre genérico de Catastro de Ensenada, proyecto de Única Contribución, que se llevaría a cabo bajo el reinado de Fernando VI. Mediante el Real Decreto de 10 de octubre de 1749, y bajo el mando del secretario de hacienda Zenón de Somodevilla, Marqués de la Ensenada, se procedería a realizar un catastro en las 22 provincias de la Corona de Castilla a fin de unificar la amalgama de impuestos y tributos que caracterizaban el Antiguo Régimen, para conseguir una tributación moderna. El Catastro se desarrollaría en dos niveles, el municipal, cuyas informaciones se obtendrían a través de las respuestas a 40 preguntas relativas al municipio (Respuestas Generales), y el individual, donde declararían sus riquezas cada una de las personas jurídicas, seglares y eclesiásticas (Libro de Hacienda), de las que previamente se habría registrado su situación personal y profesional (Libro de lo Personal). Es este Libro de lo Personal donde se detallan entre los datos personales, las profesiones y utilidades de éstas, en caso que las hubiese, de la nómina de individuos.

32 De entre los 11 concejos que a día de hoy conservan al menos parte de sus respectivas Respuestas Particulares del Catastro de Ensenada, hemos elegido cinco lugares de costa, seis muestras representativas del interior y dos concejos de montaña. 
FIGURA 1

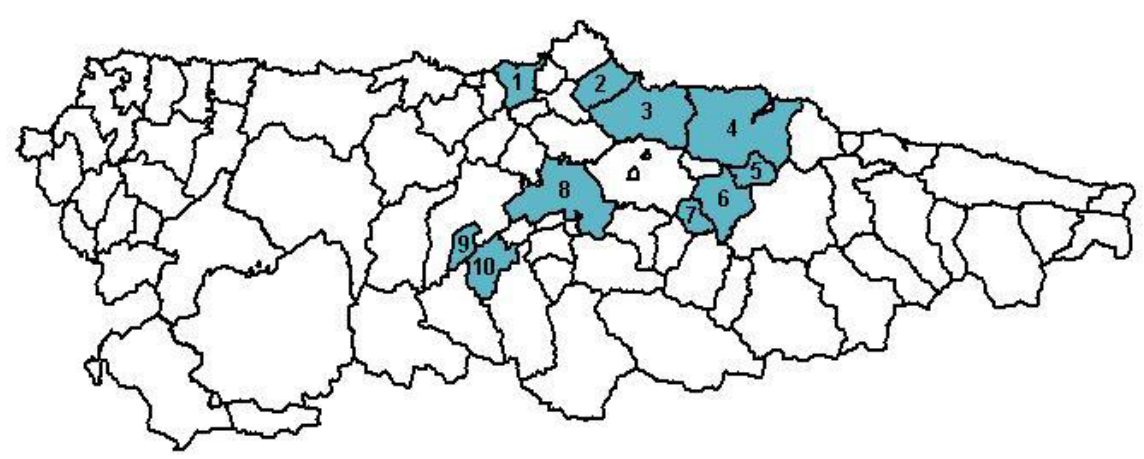

Señalados sobre el mapa con la división concejil actual, figuran los concejos estudiados. 1.Castrillón, 2.Carreño, 3.Gijón, 4.Villaviciosa (donde se incluía el Coto de Valdediós), 5.Cabranes, 6.Nava (donde se encontrabael Coto de Castañera), 7.Bimenes, 8.Oviedo (del que forman parte actualmente el antiguo concejo de Tudela y el Coto de Puerto), 9. Tameza y 10.Proaza.

Como resulta lógico a tenor de las zonas de estudio, la mayor parte de las mujeres a las que se les consigna un oficio en el Catastro de Ensenada, apuntan el de labradora como trabajo principal, siendo éste, de forma habitual, exclusivo. Sin embargo en ocasiones parece existir un silencio en torno a los oficios femeninos, pues no son pocas las veces que se omite la información laboral, especialmente en el ámbito rural, pues las mujeres sólo son anotadas como labradoras en tanto en cuanto son cabezas de familia ${ }^{33}$, e incluso dándose esta circunstancia, no siempre se consigna su ocupación. A pesar de ello las hemos contabilizado para nuestro estudio, pues la dinámica general de los datos manejados nos lleva a considerarlas como trabajadoras de la tierra, máxime, en el caso de aquellas que detentaban la jefatura de un hogar -viudas, solteras, o mujeres "abandonadas"-.

Empecemos pues por aquellas mujeres que debían subsistir con los beneficios producidos por sus labores agrarias. Este grupo estaría formado

33 LÓPEZ IGLESIAS, Florentino, "Oficios y actividades de las mujeres ovetenses en el Antiguo Régimen” en MATILLA, María Jesús y ORTEGA, Margarita, Actas de las VI Jornadas de Investigación Interdisciplinaria sobre la mujer. El trabajo de las mujeres: Siglos XVI-XX, Universidad Autónoma de Madrid, Madrid, 1996, pág. 117. 
mayoritariamente por viudas, figurando en segundo lugar las solteras, y anotando también algunos otros ejemplos, la mayoría de estos, eran mujeres casadas con maridos ausentes, las denominadas "viudas de vivos"34.

A este respecto debemos indicar que entre todos los casos estudiados, únicamente a una mujer casada se la reseña como trabajadora del campo, y es Inés Rivera, de Tameza, de quien también se nos dice que durante seis meses al año ejerce de tejedora.

Esta omisión de las casadas entre la nómina de labradores no debe llevarnos a engaño; el no aparecer en el catastro como tales, no significa que no trabajaran en las labores agroganaderas, sino que responde más bien al hecho de contabilizar únicamente el trabajo femenino cuando éste era remunerado. A pesar de la dificultad de detectar el trabajo femenino ${ }^{35}$, la norma general es localizarlos mejor en la documentación urbana que en la rural, y sobremanera en la de carácter fiscal ${ }^{36}$.

Parece obvio que, al menos, las mujeres casadas a quienes se les consigna un oficio ayudarían igualmente en las labores agrícolas diarias de su familia $^{37}$, por lo que la idea de un pluriempleo sumergido no parece descabellada en la Asturias del XVIII.

Entre los ejemplos de profesiones femeninas del ámbito rural, destaca el de panaderas y los ejercicios ligados a la industria textil, la cual trataremos posteriormente. De los 27 casos de pluriempleo rural documentados, la elaboración del pan representaría el 29,6\% del total, siendo pues, una de las ocupaciones a la que las campesinas asturianas acudirían para reforzar su maltrecha economía de subsistencia. En el caso de Cabranes nos encontramos con 7 panaderas, de las que únicamente 3, figuran a su vez como labradoras; en el concejo de Carreño son 15 los casos, aunque, a priori, sólo 2 de ellas parecen compaginar la elaboración del pan con el trabajo de la tierra. Sí resulta curioso sin embargo, que sea precisamente en la rasa costera donde figuren las panaderas de maíz o boroñeras, pues también nos las encontramos en el vecino concejo de Gijón, pudiendo responder esto al hecho de que, una vez introducido, el maíz iría ganando terreno al mijo y al panizo, sobre todo en las parroquias de marina y en los valles precosteros ${ }^{38}$.

Pese a no haber localizado panaderas en las zonas limítrofes con la capital -Coto de Puerto y Concejo de Tudela- es muy probable que existiera

34 RIAL GARCÍA, Serrana y REY CASTELAO, Ofelia, "Las viudas de Galicia a fines del Antiguo Régimen” en Chronica Nova, 34, Granada, 2008, pág. 91.

35 REY CASTELAO, Ofelia y RIAL GARCÍA, Serrana, Historia de las mujeres en Galicia. Siglos XVI al XIX, Nigratrea, Vigo, 2009, pág. 102.

36 Ibidem, pág. 119.

37 Ibidem, pp. 103-119.

38 ANES, Gonzalo, "Edad Moderna II: El Antiguo Régimen: Economía y sociedad” en Historia de Asturias Vol. VII, Ayalga, Vitoria, 1977, pág. 66. 
alguna, pues desde el siglo XVI, era común que las panaderas de las aldeas se acercaran a la ciudad a vender sus productos, siendo además normalmente bien recibidas ya que de este modo los vecinos disponían de otra fuente de abastecimiento de pan cocido. Asimismo las propias autoridades también se mostraban más permisivas con estas panaderas, pues en ocasiones podían vender en la plaza pública sin que se les controlara el peso ni el precio de sus productos ${ }^{39}$.

En relación con la elaboración del pan podemos considerar el oficio de molinera, el cual se configuraba como uno de esos "espacios masculinos" vetados a la mano de obra femenina, y al que únicamente accedían con su condición de viudedad, momento en que serían "jefas de sí mismas" "40, como usufructuarias del negocio ${ }^{41}$. En Carreño contamos con dos ejemplos, el de María González Posada de 44 años y el de Isabel del Busto de 60, ambas viudas y cabezas de familia, la primera con un hijo menor, y la segunda sin familia alguna. El uso del molino, les reportaba 164 y 100 reales respectivamente por lo que parece la transformación del pan, un sustento extra recomendable.

Este acceso de mujeres viudas -y también de "viudas de vivos"- a los negocios familiares podemos comprobarlo en otros casos estudiados. Josefa Álvarez, vecina de L'Aspra en el concejo de Castrillón, y viuda de 28 años, aparece como vendedora de vino, quizás porque su difunto marido se encontraba ya al frente de la taberna local. Más claro se nos muestra el ejemplo, aunque en el ámbito urbano, de Bárbara Andrea de la Viña Hevia, viuda de 38 años, quien además de regentar una tienda se especifica en el catastro que tenía "a su cargo una platería que le quedó por muerte de su marido", en la que empleaba a un oficial y la cual le reportaba unos beneficios de 547 reales y medio.

En lo tocante a las estanqueras, ocupación que representaba el 14,8\% sobre el total de las pluriempleadas rurales, también nos encontramos con varios ejemplos. Dos de ellos se localizan en Proaza, donde de los cinco estancos de tabaco dos estaban regidos por mujeres, uno por una viuda, y el otro por María González, quien tras haber sido abandonada por su marido "ausente mucho tiempo haze, sin saver su paradero", comenzó a compaginar su ejercicio de labradora con la atención del estanquillo de tabaco, que por estar situado en un Camino Real, le rentaba 200 reales anuales.

39 FERNÁNDEZ ÁLVAREZ, José Manuel, La Panera de Oviedo. Subsistencia y pósitos en el siglo XVI, KRK, Oviedo, 2008, pág. 290.

40 RIAL GARCÍA, Serrana y REY CASTELAO, Ofelia, "Las viudas de Galicia...”, pág. 94. 41 Véase al respecto, entre otros, pese a referirse a oficios agremiados, VICENTE VALENTÍN, Marta, "Mujeres artesanas en la Barcelona Moderna" en VV. AA., Las mujeres en el Antiguo Régimen. Imagen y realidad (s. XVI-XVIII), ICARIA, Barcelona, 1994, pp. 68-74. Igualmente, REY CASTELAO, Ofelia y RIAL GARCÍA, Serrana, Historia de las mijeres..., pág. 105. 
Ejemplo curioso es el de Isabel de Villarrica, vecina del Coto de Valdediós y mujer soltera, quien pese a su estado civil, regentaba el estanquillo de tabaco a la vez que trabajaba la tierra. Será también en este mismo Coto donde nos encontremos con otro caso interesante; José Fernández de 48 años y casado, ocupaba el cargo de panadero del Monasterio Cisterciense de San Salvador de Valdediós, oficio éste que parece estar copado casi en exclusiva por mujeres ${ }^{42}$.

\section{TABLA 1}

\begin{tabular}{|c|c|c|c|}
\hline \multicolumn{4}{|c|}{ PLURIEMPLEO RURAL FEMENINO } \\
\hline OFICIO & $\mathbf{\%}$ & ESTADO CIVIL & $\%$ \\
\hline TEXTIL & $40,70 \%$ & VIUDAS & $62,90 \%$ \\
\hline PANADERAS & $29,60 \%$ & SOLTERAS & $18,50 \%$ \\
\hline ESTANQUERAS & $14,80 \%$ & MARIDO AUST. & $11,10 \%$ \\
\hline MOLINERAS & $7,40 \%$ & CASADAS & $3,70 \%$ \\
\hline ARRIERAS & $3,70 \%$ & HERMANA DE V. & $3,70 \%$ \\
\hline TABERNERAS & $3,70 \%$ \\
& \multicolumn{2}{|c}{} \\
\hline
\end{tabular}

El "sector textil" sería otra de las ocupaciones a las que las mujeres asturianas acudían en busca de ingresos extraordinarios, pues en prácticamente todas las áreas estudiadas aparecen labradoras que compaginan sus quehaceres con oficios como los de tejedoras o costureras. Parece que las preocupaciones que Campomanes plasmaría unos años después en su obra Discurso sobre el fomento de la industria popular, ya se venían practicando en cierta medida, pues nos encontramos además de con la tamezana anteriormente señalada, con abundantes casos de viudas y solteras que apuntalan su economía con este tipo de ocupaciones, que llegaba a representar el 40,7\% del pluriempleo femenino en el mundo rural.

Respecto a las solteras que se ocupaban en la industria textil, especialmente costureras, cabría preguntarse si su objetivo final no sería el de formarse una dote con la que tener mayores probabilidades de acceso a un matrimonio provechoso, posibilidades que se alejarían una vez traspasada la línea de la treintena de años ${ }^{43}$.

42 REY CASTELAO, Ofelia y RIAL GARCÍA, Serrana, Historia de las mijeres... pp. 121-123. 43 MENÉNDEZ GONZÁLEZ, Alfonso, El barranco..., pág. 54. 
Dentro de ese 40,7\% también nos encontramos con casos de mujeres viudas quienes es probable viesen en el oficio de tejedora un atisbo de esperanza para no caer en los ciclos de pobreza coyuntural a los que se refería S. Woolf ${ }^{44}$. Asimismo contabilizamos algún caso de mujer casada, quienes por este medio aportaban unos ingresos extra al grupo familiar.

Este mismo panorama lo encontramos entre aquellas mujeres que no aparecen contabilizadas como trabajadoras de la tierra, pero que con toda probabilidad si formarían parte activa en las diferentes labores agrarias.

La importancia de la "industria textil" como ocupación femenina, bien total bien complementaria, podemos comprobarla nuevamente en los ámbitos urbanos y semiurbanos estudiados -la ciudad de Gijón, y las villas de Candás y Villaviciosa- pues también aquí nos encontramos con la existencia de mujeres, de todos los estados civiles, dedicadas a los trabajos de tejer, hilar y coser.

Sí resulta más llamativo el caso de cuatro mujeres de Carreño que se ocupaban como tratantes en lino, hecho ampliamente sugerente puesto que solía ser la trajinería un oficio ejercido por hombres. Las mujeres, dos viudas y dos solteras, obtenían unos beneficios en consonancia con el número de cargas que acarreaban desde Castilla, ganando desde los 60 reales por un viaje, hasta los 540 que se obtenían de nueve cargas de lino.

Pero no se acababa aquí el abanico profesional femenino. De entre las diversas actividades en que nos encontramos a mujeres, merece la pena destacar el caso de las escabecheras, pues tanto en Candás como en Gijón, es un oficio que aparece totalmente copado por mujeres, casadas en el $85,7 \%$ de los casos, hecho este último que viene a rebatir la opinión de Menéndez González quien afirmaba que se conformaba esta ocupación como la "última oportunidad de las mujeres solteras"45. La ocupación de escabechera, sería por tanto una posible salida a la búsqueda de ingresos alternativos para la familia, cuyo cabeza solía dedicarse a tareas relacionadas con el mar en el 83,3\% de los casos, tratándose de marineros en un 66,6\%. Asimismo los ingresos obtenidos por las mujeres con esta ocupación podían alcanzar cantidades relativamente importantes si las comparamos con otras remuneraciones con que eran satisfechos los trabajos femeninos, llegando en ocasiones a unos ingresos de 1.100 reales al año.

También ligadas a las actividades pesqueras, estaban las vendedoras de grasa de ballena, constituyendo otro claro ejemplo de búsqueda de ingresos alternativos para el grupo familiar, pues en más del 50\% de los casos vistos, estas mujeres estaban casadas. Como dato resaltable señalar que, a excepción de una mujer, estas vendedoras o sus maridos aparecían regentando una tienda.

44 WOOLF, Stuart, Los pobres en la Europa Moderna, Crítica, Barcelona, 1989.

45 MENÉNDEZ GONZÁLEZ, Alfonso, El Barranco... pág. 100. 
$\mathrm{Al}$ igual que las anteriores, las muchachas que se empleaban como sirvientes funcionaban como un sustento económico extra para el hogar. En la mayoría de las ocasiones estas funciones las desarrollaban hijas de mujeres tanto viudas como casadas, mozas solteras al fin y al cabo, quienes quizás vieran también en el servicio doméstico cierta esperanza de ahorrar dinero para su dote, proyecto que en ocasiones verán frustrado debido a la práctica común de ir acumulando salarios impagados año tras año. No obstante esto se vería parcialmente "solucionado" en algunas ocasiones con las mandas testamentarias, en las que, especialmente las señoras, solían ser más generosas para con sus criadas ${ }^{46}$.

Si bien estas mujeres formaban parte del grueso de las trabajadoras, existen varios ejemplos que nos llevan a pensar en la existencia de "pro mujeres" en Asturias.

En elconcejode Gijón, ToribiaMorán, viuda de 52años, nosla encontramos desarrollando otra de esas funciones masculinas, el de administradora de rentas del Marqués de San Esteban, trabajo que le reportaba una utilidad anual de 820 reales. ¿Estaremos ante otro ejemplo de labor heredada? En el caso de Doña Josefa de Prendes parece ser que sí, ya que se encontraba al frente de una botica en la Calle Los Moros de la misma villa, de la que, sin embargo obtenía escasos beneficios si los comparamos con los logrados por algunos boticarios del sexo opuesto.

Otra viuda gijonesa, Doña Manuela Suárez del Rosal, era una importante comerciante de azabache, en cuyo caso no podemos hablar de "discriminación" salarial, pues a la luz de la documentación ganaba lo mismo que el resto de comerciantes, e incluso superaba a algunos, 1.460 reales.

De los concejos tomados como ejemplo sólo encontramos a otra vecina que se ocupaba en el comercio del mismo género. Doña María Antonia Álvarez, igualmente viuda, vecina de la parroquia de Villaverde en Villaviciosa, una de las localidades azabacheras por excelencia, ganaba 600 reales al año por esta actividad, superando a su competidor masculino, quien solo sacaba de provecho 100 reales. El resto de la población, principalmente hombres, se ocupaban de las labores de manufactura y extracción del mineral.

Precisamente es en la capital del concejo de Villaviciosa, donde se refrenda la teoría del predominio de solteras en el mercado laboral urbano, frente a las viudas ${ }^{47}$, contrariamente a lo que ocurría en el mundo rural, dónde la viudedad era el estado cuasi habitual entre las trabajadoras.

46 LÓPEZ IGLESIAS, Florentino, “Los criados en la Asturias del Antiguo Régimen” en BIDE $A$, 150, Oviedo, 1997, y MENÉNDEZ GONZÁLEZ, Alfonso, El Barranco..., pp. 100-112.

47 REY CASTELAO, Ofelia y RIAL GARCÍA, Serrana, Historia de las mijeres... pp. 120-121. 


\section{CONCLUSIONES}

Hemos visto pues como en el siglo XVIII, escritores e ilustrados han proyectado una imagen de la mujer, para bien o para mal, en buena medida utópica.

Las coyunturas económicas y sociales del Siglo de la Razón, terminaron con el ideal de mujer doméstica, abogando por la salida del hogar de ésta, reconociéndoles el derecho a la educación y su utilidad en el trabajo extra doméstico.

Desconocemos si las mujeres que trabajaban en la Asturias del siglo XVIII eran juiciosas y prudentes, si podían encajar en los salones de las Sociedades Económicas o simplemente, si sabían leer o escribir, pero la inteligencia y capacidades que muchos autores defendían se pusieron de relieve a la hora de gestionar una platería o de comerciar con azabache.

Aunque la ausencia del varón fuese a veces determinante en la elección del oficio, las mujeres del Principado serían vendedoras al por menor, arrieras, estanquilleras, taberneras, saineras, fruteras, confiteras, sardineras e incluso porteras, complementando, en algunos casos, los oficios del marido, hecho que se observan en "binomios profesionales" como los de molineropanadera, marinero-escabechera o maestro zapatero-vendedora de cordones.

Se demuestra así, muy a pesar de Campomanes, como el mundo del trabajo femenino no se reducía al ámbito textil, estando, nuestras asturianas, más allá del telar. 